\title{
Glomerular Hypertrophy
}

National Cancer Institute

\section{Source}

National Cancer Institute. Glomerular Hypertrophy. NCI Thesaurus. Code C96239.

A morphologic finding indicating enlargement of the glomeruli in a kidney specimen. 